\title{
Impact of firing temperature on insulating properties of Low Temperature Co-fired Ceramics
}

\author{
ARKADIUSZ P. DABROWSKI* \\ Wroclaw University of Science and Technology, Faculty of Microsystem Electronics and Photonics, Wybrzeze Wyspianskiego \\ 27, 50-370 Wroclaw, Poland

\begin{abstract}
In this paper, results of investigation on the impact of firing temperature on insulating properties of Low Temperature Co-
\end{abstract} \\ fired Ceramics are presented. Dissipation factor, volume resistivity and breakdown electric field intensity were determined for \\ firing peak temperature in the range from $800{ }^{\circ} \mathrm{C}$ to $900{ }^{\circ} \mathrm{C}$. The tests were performed for two commercial LTCC materials: \\ 951 Green Tape (DuPont, USA) and SK47 (Keko, Slovenia). The results showed that the firing temperature had a significant \\ effect on the dielectric loss factor, volume resistivity and lifetime at applied high voltage. No clear tendency was observed for \\ dielectric strength in the analyzed firing temperature range.
}

Keywords: LTCC; ceramics; breakdown; volume resistivity; high voltage

\section{Introduction}

Low Temperature Co-fired Ceramics (LTCC) is an attractive material for fabrication of microelectronic circuits with embedded passive components like resistors, capacitors and inductors [1]. Thanks to its very good electrical and mechanical properties as well as thermal and chemical stability, various fields of application are possible. The LTCC is widely used for fabrication of microwave components $[2,3]$, high temperature devices $[4,5]$, microreactors for harsh media [5, 6], various environmental sensors [7-9] as well as specialized packages $[4,10]$. The LTCC exhibits superior insulating properties, including high dielectric strength and high volume resistivity $[11,12]$. The properties make the material suitable for fabrication devices that work at high potential difference between its terminals, e.g. in miniaturized transformers with high voltage insulation [12].

From the point of view of insulating properties and reliability aspects in devices working under high voltage conditions, important stages of the LTCC process are material selection and quality of screen printing, lamination and firing processes. Typical materials applied for metallization in the

*E-mail: arkadiusz.dabrowski@pwr.edu.pl
LTCC modules are thick-film pastes based on silver, gold and silver-palladium conductive phases. The most common is silver, because of low resistivity and low cost, however, the material is susceptible for diffusion during the firing process and migration during operation [13]. As a result, during the screen printing process, unintended contamination should be avoided in insulating areas, in order to limit the leakage current at high electric field intensity. Poor quality of lamination process can also affect the insulating properties, resulting from voids existence in the dielectric material. Nevertheless, even the best quality of mentioned processes does not guarantee the best insulating properties. The final structure of the material is formed during firing process, especially during the final step of the process, at the highest temperature. In general, the porosity of the LTCC material decreases with increasing maximum temperature of firing in the range between $800{ }^{\circ} \mathrm{C}$ and $900{ }^{\circ} \mathrm{C}[14,16]$. The porosity of the LTCC material reaches almost constant value of $1 \%$ for firing temperature range of $850{ }^{\circ} \mathrm{C}$ to $900{ }^{\circ} \mathrm{C}$, while still $7 \%$ porosity can be observed after firing at $800{ }^{\circ} \mathrm{C}$ [14]. In spite of reduction of porosity, density of the material can also be reduced with increasing firing temperature. The effect is the result of formation of low density phases during the sintering process [15]. 
The densification of the material can also be affected by a temperature increase to the peak temperature [17]. During the firing process, crystalline phases are formed in the most common LTCC materials, like e.g. 951 (DuPont) [14, 18], A6M (Ferro) [15, 16], 41111-G (ESL) [17]. Higher firing temperature results in higher rate of crystalline phase formation. During standard firing process of 951 ceramics with 15 -minutes hold at the peak temperature, crystallites are growing above temperature of $850{ }^{\circ} \mathrm{C}$. In such conditions, the mass fraction of crystalline phase is below $1 \mathrm{wt} . \%$, whereas at $875{ }^{\circ} \mathrm{C}$ and $900{ }^{\circ} \mathrm{C}$ the mass fraction of the phase is at the level of $2 \mathrm{wt} . \%$ and $12 \mathrm{wt} . \%$, respectively [14]. Also an important factor is a hold time at the peak temperature. If the time is extended to few hours, the crystalline mass fraction is the same for firing temperatures between $850{ }^{\circ} \mathrm{C}$ and $900{ }^{\circ} \mathrm{C}$, with the final value of about 20 wt.\% [14]. Moreover, if the ceramic material is held at $800{ }^{\circ} \mathrm{C}$ for $100 \mathrm{~h}$, the same final level of crystalline fraction can be reached in the case of the 951 material [18]. Higher firing temperature and longer hold time lead to the growing grain size in the LTCC material [15].

Differences in the LTCC microstructure result in different mechanical and electrical properties of the material. For example, a maximum flexural strength is observed for higher firing temperatures [14]. The dissipation factor and the dielectric constant of the LTCC decreases with firing temperature, however above $850{ }^{\circ} \mathrm{C}$ the values are almost constant in case of A6M material [16]. Nevertheless, even a few degrees of temperature difference can affect the dielectric properties, especially at high frequency [19].

In this paper, results of investigation on the impact of firing temperature on insulating properties of Low Temperature Co-fired Ceramics are presented. The dissipation factor, volume resistivity and breakdown electric field intensity were determined for firing peak temperature in the range between $800{ }^{\circ} \mathrm{C}$ and $900{ }^{\circ} \mathrm{C}$. Time to breakdown was also determined at various elevated temperatures. The tests were performed for two LTCC materials: 951 Green Tape (DuPont, USA) and SK47 (Keko, Slovenia).

\section{Test samples}

Test samples were made of two commercially available LTCC tapes: 951 Green Tape (DuPont, USA) and SK47 (Keko, Slovenia). Both materials had a thickness of $165 \mu \mathrm{m}$ before firing, in order to assure enough mechanical strength during the process and tests. However for breakdown tests at room temperature, the thickness of $114 \mu \mathrm{m}$ was chosen, because of $15 \mathrm{kV}$ voltage limit of applied high voltage supply (CA6555, Chauvin Arnoux, France). First, the green tapes were laser cut to squares of $50 \times 50 \mathrm{~mm}^{2}$. A proper alignment markers for precise two-sided metallization alignment were also cut on the substrates. The silver paste 6145 (DuPont) was screen printed consecutively on both sides of the samples as electrodes. In the center of the substrate, the round-shaped electrodes with diameter of $4 \mathrm{~mm}$ after firing, were made. Prior to firing, the single layer tapes were pressed under $20 \mathrm{MPa}$ at $70{ }^{\circ} \mathrm{C}$ for 5 minutes, as in a typical LTCC process. The pressing was important for final properties of the LTCC material, because it could influence densification and shrinkage of the material. Finally, the samples were fired at different peak temperatures: $800{ }^{\circ} \mathrm{C}, 812{ }^{\circ} \mathrm{C}$, $825^{\circ} \mathrm{C}, 837{ }^{\circ} \mathrm{C}, 850{ }^{\circ} \mathrm{C}, 862{ }^{\circ} \mathrm{C}, 875^{\circ} \mathrm{C}, 887^{\circ} \mathrm{C}$ and $900{ }^{\circ} \mathrm{C}$. The temperature was held for 20 minutes. The only difference between the applied firing time-temperature profiles was the peak temperature, whereas the rate of temperature changes was the same, according to firing schedule recommended by 951 Green Tape manufacturer.

\section{Measurement}

The insulating properties were determined in different conditions. Measurement of the dissipation factor as well as the breakdown voltage, were carried out at room temperature. Measurement of the volume resistivity and the accelerated aging tests were performed at elevated temperature. The applied test setup is presented in Fig. 1. The temperature of the hotplate was controlled by a temperature controller. The temperature of the sample was measured using a thermocouple. The hotplate acted as a contact to the bottom electrode of the sample 
and the top electrode was contacted with a pressure probe. The megaohmmeter CA6555 (Chauvin Arnoux, France) was used as a high voltage source. The device allowed measuring of applied voltage and current simultaneously. Temperature of the hotplate and test voltage were controlled and the data from the devices were acquired using a software prepared in LabView environment. The setup was applied for all measurement requiring high voltage. Example of the sample during the test is shown in Fig. 2. The dissipation factor was determined using the RLC bridge (4263A, Hewlett Packard) at $100 \mathrm{kHz}$, using a dedicated sample holder with pressure probes configured as a Kelvin probe.

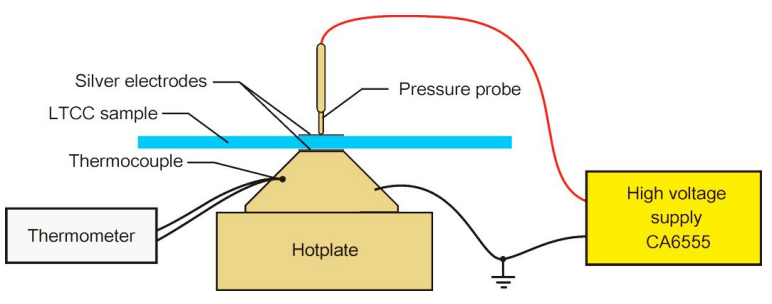

Fig. 1. Setup applied during the measurements.

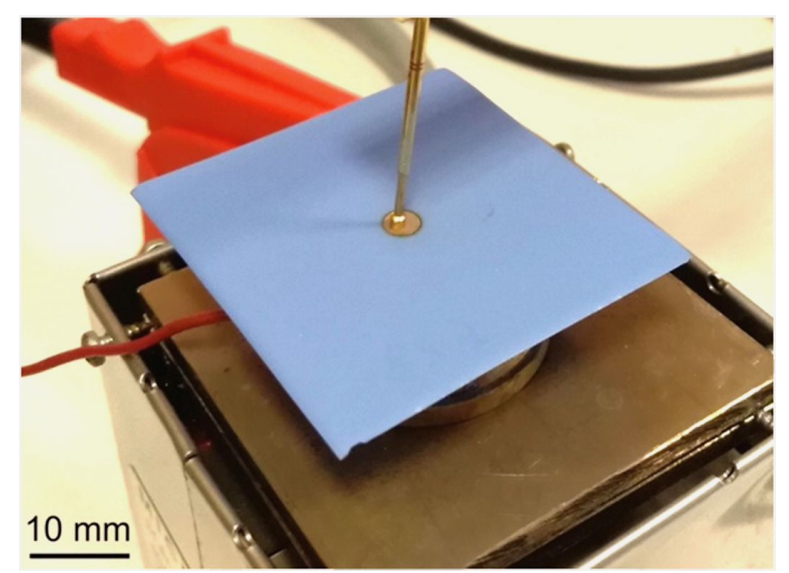

Fig. 2. Sample in test setup.

\section{Results}

\subsection{Dissipation factor}

First, the dissipation factor was determined for three samples and mean values for three samples were calculated for each firing temperature. The results are shown in Fig. 3. For both tested LTCC materials the factor reached almost constant values above $850{ }^{\circ} \mathrm{C}$, however small changes are visible with increasing firing peak temperature. The results are similar to literature data obtained for A6M material [16].

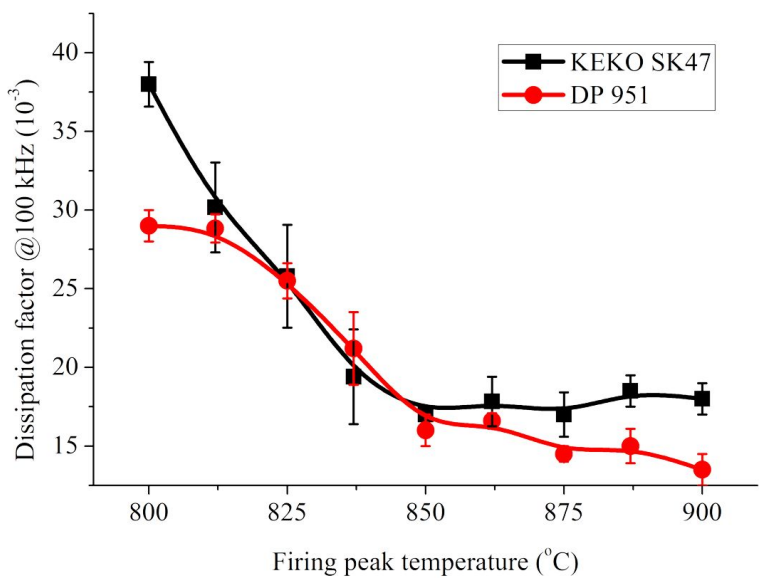

Fig. 3. Dissipation factor at room temperature measured at $100 \mathrm{kHz}$.

\subsection{Volume resistivity}

The volume resistivity was determined at elevated temperature in order to reduce the impact of air humidity during the measurements. The leakage current was determined consecutively at $200{ }^{\circ} \mathrm{C}$, $150{ }^{\circ} \mathrm{C}$ and $100{ }^{\circ} \mathrm{C}$, to exclude leakage current caused by moisture adsorbed on the sample surface. The same three samples as for dissipation factor measurement were analyzed during the test. The measurements were carried out at a constant electric field intensity of $5 \mathrm{kV} / \mathrm{mm}$ inside the material to reduce conduction through air and the surface of the sample. After the electrical measurements, dimensions of the samples were determined, including thickness of the insulator as well as an exact surface area of the electrode.

The volume resistivity $\rho$ was calculated according to formula 1 :

$$
\rho=\frac{E \cdot A}{I_{L}}
$$

where: E - electric field intensity inside dielectric material, A - surface area of the planar sample, 
$\mathrm{I}_{\mathrm{L}}$ - leakage current through the material. The results are presented in Fig. 4a. and Fig. 4b. for 951 and SK47 sample, respectively. For both materials the maximum values were obtained for samples fired in temperatures from $825{ }^{\circ} \mathrm{C}$ to $875{ }^{\circ} \mathrm{C}$. The results can be connected with the microstructure of the samples. For firing temperature below $825^{\circ} \mathrm{C}$, porosity could affect the resistivity. For the temperatures above $875{ }^{\circ} \mathrm{C}$, growing of grain size could reduce the resistivity. The effect could be explained by shorter mean paths of current flow through the material with greater grains than in the materials with smaller grains. Additionally, differences between the resistivity of the grown crystalline phases and an amorphous composition of ceramic particles in glass matrix could be important. Beside this, the resistivity could be affected by migration of silver from the electrodes into the LTCC material during firing process [20]. It is obvious, that the migration and diffusion of silver during the firing process depends on temperature. As a result, the volume resistivity could be reduced.

\subsection{Dielectric strength}

The dielectric strength was determined at room temperature for prepared samples with thickness of about $100 \mu \mathrm{m}$ after firing. Because of expected scatter of results, four samples were prepared for the tests for each firing temperature. The electric field intensity at breakdown is shown in Fig. 5. The results do not show a clear trend of the dielectric strength with changing firing peak temperature. However, the minimum values were recorded for the firing temperature of $900{ }^{\circ} \mathrm{C}$.

\subsection{Accelerated aging tests}

Accelerated aging tests were also performed for the series of the LTCC samples fired at different temperatures. Both materials exhibited different behavior under such tests, hence the long-term aging process was made at electric field intensity of $20 \mathrm{kV} / \mathrm{mm}$ at temperatures of $200{ }^{\circ} \mathrm{C}$ and $250{ }^{\circ} \mathrm{C}$ for SK47 and 951, respectively. The leakage current during aging is shown in Fig. 6a and Fig. 6b, for SK47 and 951, respectively. In case of the samples made of SK47, the leakage current was mono-

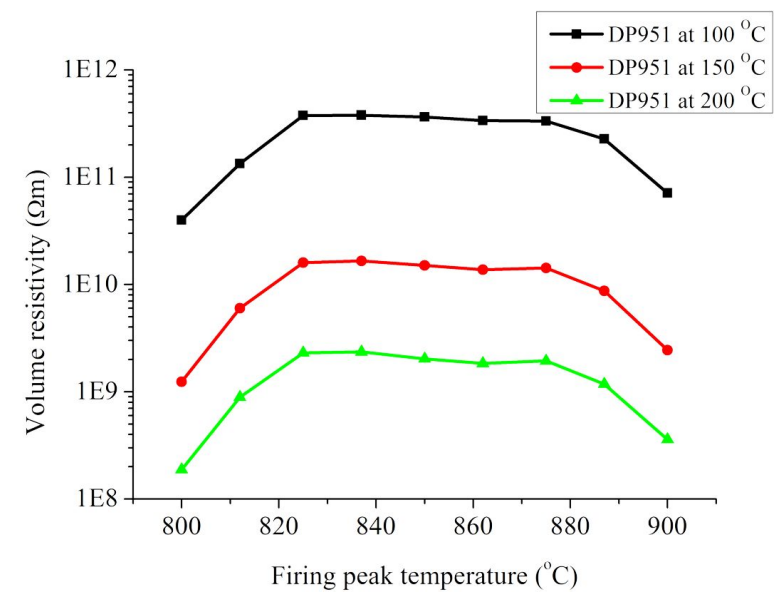

(a)

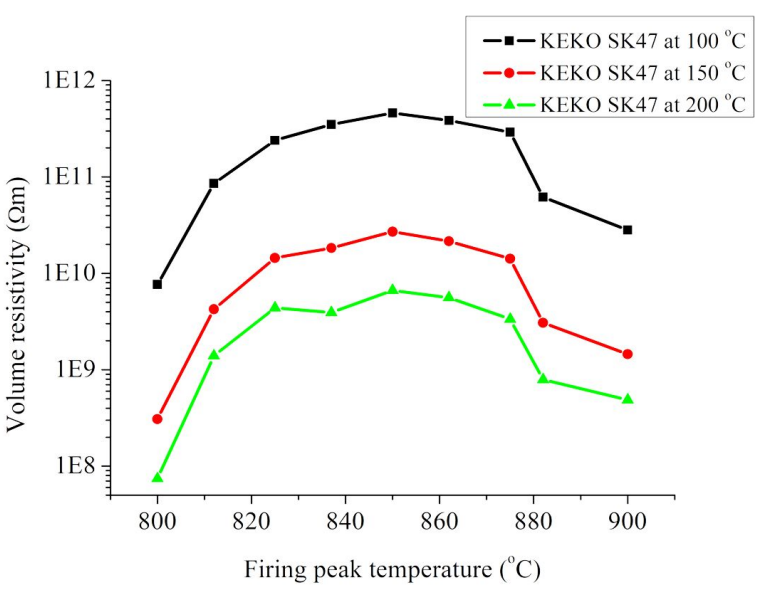

(b)

Fig. 4. Volume resistivity for DuPont 951 (a) and Keko SK47 (b) fired at different peak firing temperatures and measured at different temperatures and electric field intensity of $5 \mathrm{kV} / \mathrm{mm}$.

tonically increasing during the test, independently on firing temperature. It could be connected with electromigration of silver during the process, resulting in increasing leakage current. For the samples made of 951, decreasing of the leakage current was observed. This result suggests that no degradation of the dielectric properties occurred, but it could be connected with desorption of a water from the surface during aging. The breakdown could result also from the electromigration of silver, however it occurred in the spots of the sample, where defects or inhomogeneity due to the LTCC tape production or the technological process existed. 


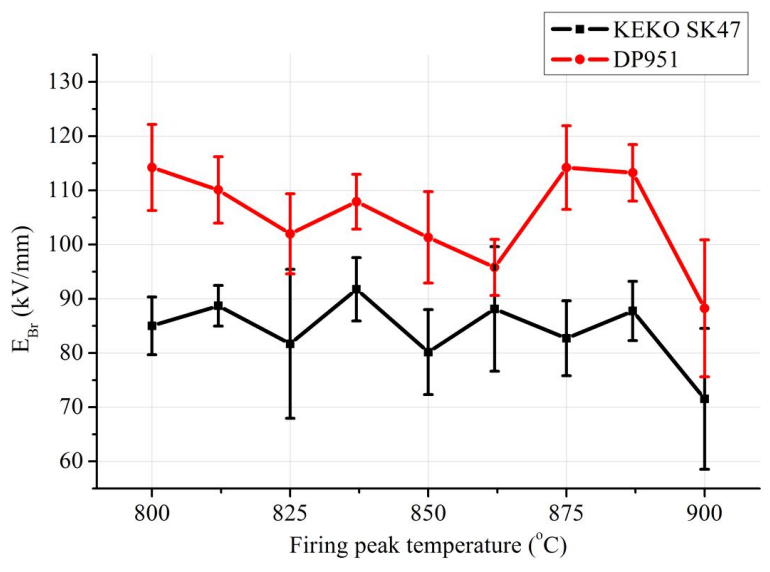

Fig. 5. Breakdown electric field intensity for DuPont 951 and Keko SK47 fired at different peak firing temperatures.

According to the performed aging process, time to breakdown of the LTCC samples was determined for all of the material and firing temperature configurations. The results are compared in Fig. $7 \mathrm{a}$ and Fig. 7b, for SK47 and 951, respectively. Despite the higher aging temperature applied for the 951 sample, the material exhibited much longer lifetime. Example of the sample after aging test is shown in Fig. 8, where the breakdown place is marked. Usually, the breakdown occurred near the edge of the electrode. In that place, the highest electric field density existed during the tests as well as different structures of the material could be formed during sintering in the regions with and without the electrode. Current flow through the surface of the sample resulted in dendrites growth around the electrode, as visible in Fig. 8. The dendrite structures had grown thanks to water chemically adsorbed on the ceramics surface, facilitating the electromigration process [13]. The water, chemically adsorbed on metal-oxide ceramics can exist up to relatively high temperatures even at $300{ }^{\circ} \mathrm{C}$, whereas physically adsorbed water can be completely removed at a temperature below $100{ }^{\circ} \mathrm{C}$ [21].

The knowledge of the lifetime at different temperatures made possible to predict the lifetime at other temperatures, for example at room temperature. In general, time to failure of a dielectric material $\tau$ depended on applied voltage, temperature and specific parameters of examined

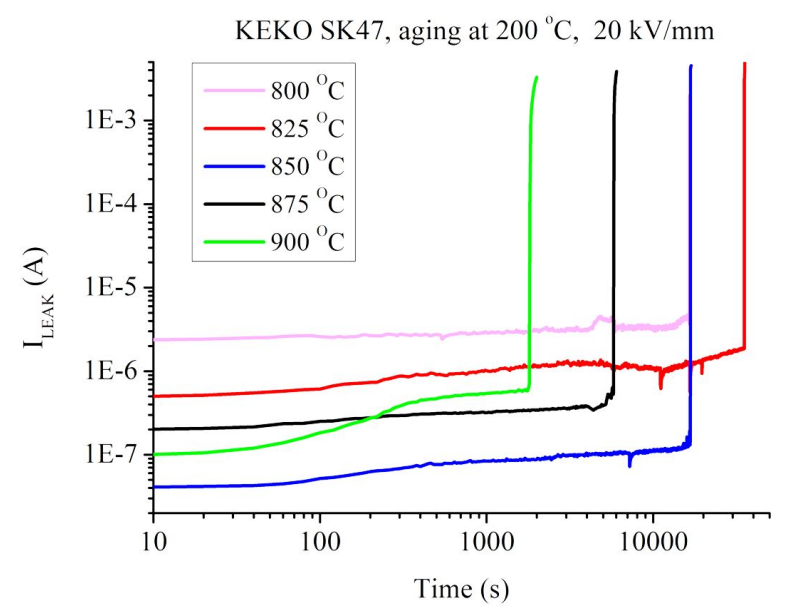

(a)

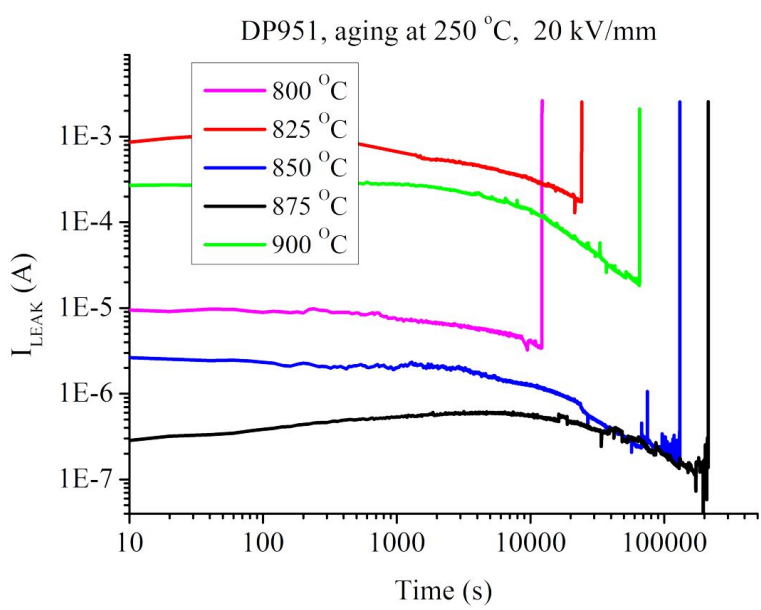

(b)

Fig. 6. Leakage current during accelerated aging test of the LTCC samples made of SK47 (a) and 951 (b) materials.

material according to formula $2[22,23]$ :

$$
\tau=A \exp \left(\frac{-E_{a}}{k T}\right) \exp \left(-\gamma E_{f}\right)
$$

where: $\mathrm{A}$ is a constant, $\mathrm{E}_{\mathrm{a}}$ - activation energy, $\mathrm{k}-$ Boltzmann constant, $\mathrm{T}$ - temperature, $\gamma$ - electric field acceleration factor, $\mathrm{E}_{\mathrm{f}}$ - electric field intensity.

Assuming a constant electric field intensity, the formula 2 simplifies to 3 :

$$
\tau=B \exp \left(\frac{-E_{a}}{k T}\right)
$$


Table 1. Aging activation energy and estimated lifetime at $150{ }^{\circ} \mathrm{C}$.

\begin{tabular}{ccccccc}
\hline \multicolumn{2}{l}{ Firing peak temperature } & $800{ }^{\circ} \mathrm{C}$ & $825{ }^{\circ} \mathrm{C}$ & $850{ }^{\circ} \mathrm{C}$ & $875{ }^{\circ} \mathrm{C}$ & $900{ }^{\circ} \mathrm{C}$ \\
\hline \hline \multirow{2}{*}{ Ea (eV) } & SK47 & 0.66 & 0.82 & 0.68 & 0.75 & 0.99 \\
& DP951 & 2.16 & 2.44 & 2.79 & 1.82 & 1.33 \\
\hline \multirow{2}{*}{$\tau_{150 ~ C}(\mathrm{~h})$} & SK47 & 32 & 105 & 33 & 13 & 9 \\
& DP951 & $2.9 \cdot 10^{5}$ & $2.4 \cdot 10^{6}$ & $8.4 \cdot 10^{7}$ & $8.6 \cdot 10^{5}$ & $1.9 \cdot 10^{4}$ \\
\hline
\end{tabular}

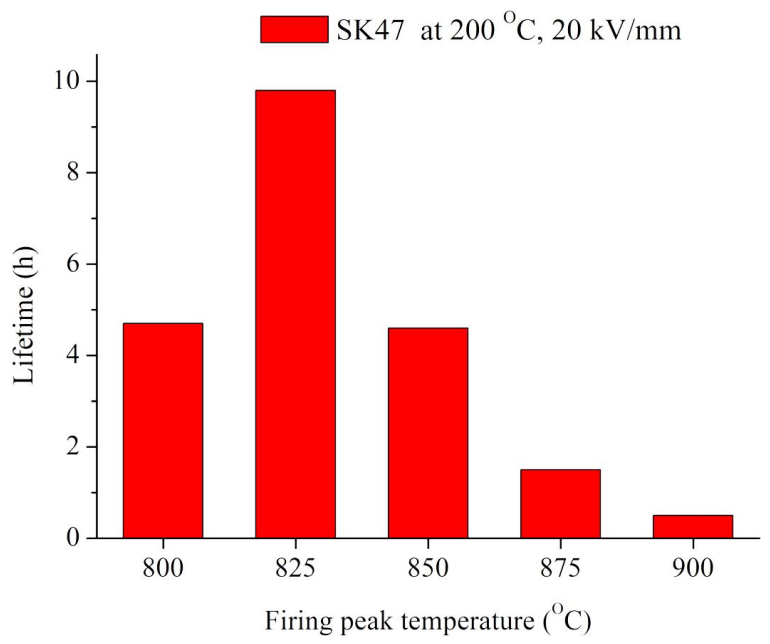

(a)

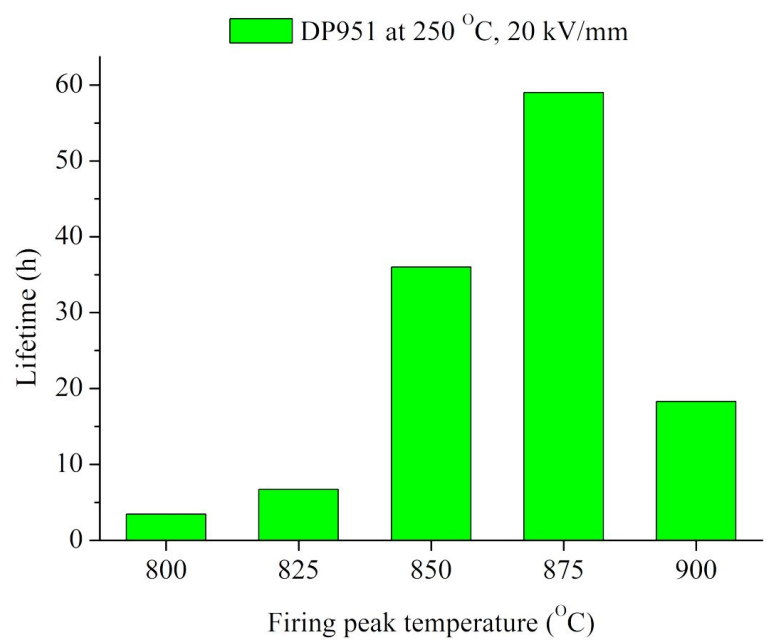

(b)

Fig. 7. Lifetime of samples made of SK47 (a) and 951 (b) under specified aging conditions.

where: $\mathrm{B}$ is a constant. The lifetime (time to failure) of the samples fired at different temperatures was determined at selected temperatures in the range between $200{ }^{\circ} \mathrm{C}$ and $300{ }^{\circ} \mathrm{C}$. The results are shown

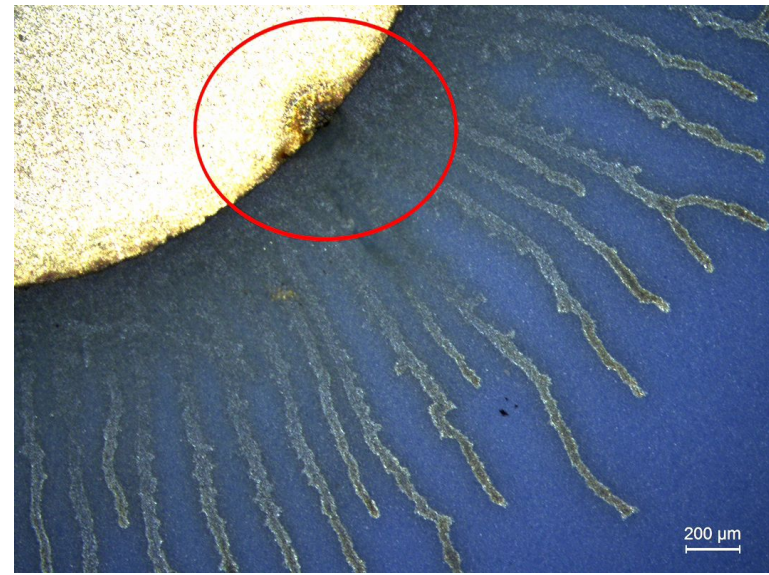

Fig. 8. Example of sample after aging test.

in Fig. 9a and Fig. 9b for SK47 and 951, respectively.

An activation energy of dielectric degradation process was calculated based on the obtained results and is shown in Table 1 . Additionally, the predicted lifetime of the ceramic dielectric at $150{ }^{\circ} \mathrm{C}$ was estimated and compared. The samples made of SK47 exhibited poor lifetime, so the material is not suitable for high voltage devices. In case of 951 material, the samples fired at peak firing temperatures between $825{ }^{\circ} \mathrm{C}$ and $875{ }^{\circ} \mathrm{C}$ exhibit satisfactory lifetime for operation at temperature of $150{ }^{\circ} \mathrm{C}$, which is maximum operating temperature for standard active electronic components [24].

\section{Summary}

Insulating properties of two LTCC materials were determined. The dissipation factor strongly depended on peak firing temperature, however the value was almost constant for the samples with peak firing temperature above $850{ }^{\circ} \mathrm{C}$. The volume resistivity 


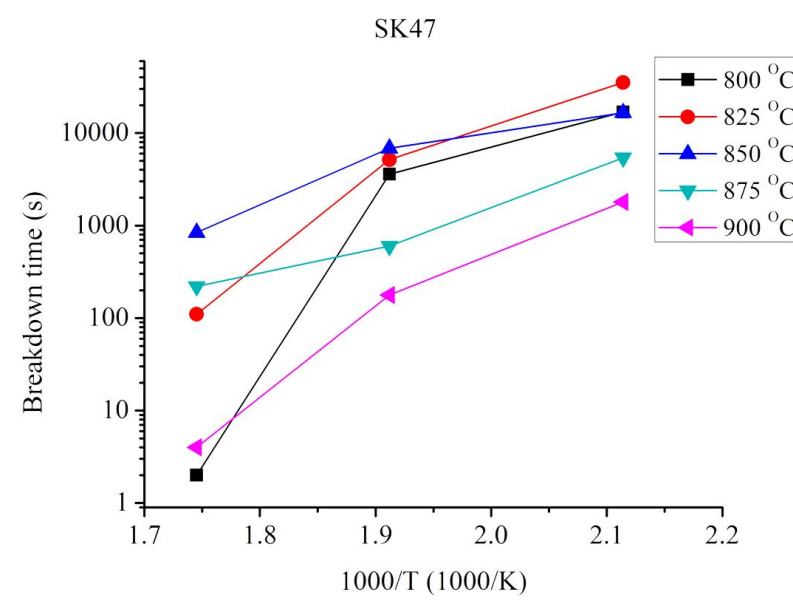

(a)

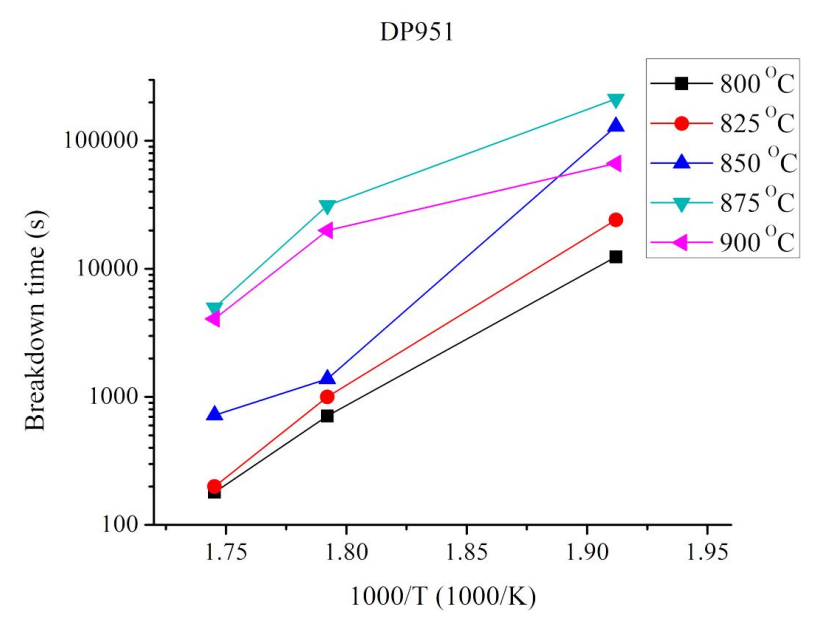

(b)

Fig. 9. Breakdown time vs. aging temperature for SK47 (a) and 951 (b).

reached maximum value for firing temperature between $825{ }^{\circ} \mathrm{C}$ to $875^{\circ} \mathrm{C}$. The mentioned dependencies were explained based on the material microstructure properties. No clear influence of firing peak temperature on the breakdown electric field intensity was observed because of the scatter of the results. The measurements showed lower breakdown voltage for samples made of SK47 in comparison with 951 ones. The samples, after resistance vs. temperature measurements, were also taken for aging tests, however the samples made of SK47 were affected by previously conducted tests, probably because of migration of silver between electrodes at elevated temperature. For the samples made of 951, such deterioration of insulating properties was not observed and the samples exhibited stable properties after consecutive tests at elevated temperature. Calculated lifetime of the samples made of 951 was much longer than that of SK47 material, hence the 951 material could be more suitable for high-voltage application at elevated temperature. In addition, all results of the investigation showed the best properties of material 951 for those samples that were fired at a peak temperature of $850{ }^{\circ} \mathrm{C}$, which is also recommended by the manufacturer.

\section{Acknowledgements}

This work was supported by statutory activities of Wrocław University of Science and Technology.

\section{References}

[1] DZIEDZIC A., NOWAK D., Radioengineering, 22 (2013), 218.

[2] UR-Rehman M., AdekAnye M., TARIQ Chattha H., Nano Commun. Netw., 18 (2018), 72.

[3] Jantunen H., Kangasvieri T., VÄHÄKangas J., Leppävuori S., J. Eur. Ceram. Soc., 23[14] (2003), 2541.

[4] NOWAK D., DzIEdzIC A., Microelectron. Reliab., 51[7] (2011), 1241.

[5] Jiang B., Muralt P., Maeder T., Sensor. Actuat. BChem., 221 (2015), 823.

[6] Belavic D., Hrovat M., Dolanc G., Santo Zarnik M., Holc J., Makarovic K., Radioengineering, 21[1] (2012), 195.

[7] Ma M., Khan H., Shan W., Wang Y., OU J. Z., LiU Z., Kalantar-Zadeh K., Li Y., Sensor. Actuat. B-Chem., 239 (2017), 711.

[8] Lin L., Ma M., Zhang F., LiU F., LiU Z., Li Y., Ceram. Int., 44[1] (2018), S129.

[9] Manjakkal L., Synkiewicz B., Zaraska K., Cvejin K., Kulawik J., Szwagierczak D., Sensor. Actuat. B-Chem., 223 (2016), 641.

[10] Radauscher E.J., PARKer C.B., Gilchrist K.H., Di Dona S., Russell Z.E., Hall S.D., CARLSon J.B., Grego S., EdWARds S.J., SPERline R.P., Denton M., Stoner B.R., Glass J.T., Amsden J.J., Int. J.Mass Spectrom., 422 (2017), 162.

[11] Dorczynski M., Fabinska W., Roguszczak H., Golonka L., Proc. Device Packaging HiTEC HiTEN \& CICMT, (2016), p. 47.

[12] Dąbrowski A., Rydygier P., Czok M., GolonkA L., Microelectron. Int., 35 (2018), 146.

[13] Imanaka Y., Multilayered Low Temperature Cofired Ceramics (LTCC) Technology, Springer US, 2005.

[14] Makarovic K., Meden A., Hrovat M., Holc J., Bencan A. Dakskobler A., Kosec M., J. Am. Ceram. Soc., 95[2], (2012), 760. 
[15] Alias R., The Effects of Sintering Temperature Variations on Microstructure Changes of LTCC Substrate, in: LAKSHMANAN A. (Ed.), Sintering of ceramics - new emerging techniques, InTech, London, 2012, p. 59.

[16] Walker J. Maloney J., Gleason C., Holthus J., Smith B., Henry J., Graddy E., SRidharan S., SAKoske G., Proc. Device Packaging HiTEC HiTEN \& CICMT, (2016), p. 136.

[17] Heux A., Antou G., Pradeilles N., Delhote N., Karnfelt C., Gallee F., Maitre A., Ceram. Int., 44[18] (2018), 22609.

[18] Makarovic K., Bencan A., Hrovat M., Holc J., mali B, Kosec M., Bermejo R., Kraleva I., Int. J. Appl. Ceram. Technol., 10 [3] (2013), p. 449.

[19] Barteczka B., Slobodzian P., Dabrowski A., GOLONKA L., Microelectron. Int., 31[3] (2014), 169.
[20] Nair D., Nair K. M., Souders K., Smith M., MCCombs M., Parisi J., Mobley T., Thrasher B., (2010), Proc. International Symposium on Microelectronics: FALL 2010, Vol. 2010, No. 1, p. 242.

[21] Kawaguchi S., Namiki K.C., Ohshio S., Nishino J., Saitoha H., Adv. Mater., 11-12 (2006), p.693.

[22] Tsu R., McPherson J.W., McKee W.R., Proc. IRPS, (2000), p. 348.

[23] Noguchi J., IEEE Electron Dev., 52[8] (2005), p. 1743.

[24] Watson J., Castro G., J. Mater. Sci. Mater. Electron., 26 (2015), p. 9226.

Received 2019-01-08

Accepted 2019-07-15 